\title{
A Household-Level Activity Pattern Generation Model with an Application for Southern California
}

Chandra R. Bhat (corresponding author)

The University of Texas at Austin

Dept of Civil, Architectural \& Environmental Engr

301 E. Dean Keeton St. Stop C1761, Austin TX 78712

Tel: 512-471-4535; Fax: 512-475-8744

Email: bhat@mail.utexas.edu

\section{Ram M. Pendyala}

Arizona State University

School of Sustainable Engr and the Built Environment

Room ECG252, Tempe, AZ 85287-5306

Tel: 480-727-9164; Fax: 480-965-0557

Email: ram.pendyala@asu.edu

\section{Raghuprasad Sidharthan}

The University of Texas at Austin

Dept of Civil, Architectural \& Environmental Engr

301 E. Dean Keeton St. Stop C1761, Austin TX 78712

Tel: 512-471-4535; Fax: 512-475-8744

Email: raghu@mail.utexas.edu

\section{Hsi-Hwa Hu}

Southern California Association of Governments

818 W. Seventh Street, 12th Floor

Los Angeles, CA 90017

Tel: 213-236-1834; Fax: 213-236-1962

Email: hu@scag.ca.gov
Konstadinos G. Goulias

University of California

Department of Geography

Santa Barbara, CA 93106-4060

Tel: 805-308-2837, Fax: 805-893-2578

Email: goulias@geog.ucsb.edu

\section{Rajesh Paleti}

Parsons Brinckerhoff

One Penn Plaza, Suite 200

New York, NY 10119

Phone: 512-751-5341

Email: rajeshp@mail.utexas.edu

\section{Laura Schmitt}

Georgia Institute of Technology

School of Civil \& Environment Engineering

Mason Bldg, 790 Atlantic Dr, Atlanta, GA 30332

Tel: 704-490-7354; Fax: 404-894-2278

Email: 1schmitt3@gatech.edu

January 29, 2013 


\begin{abstract}
This paper develops and estimates a Multiple Discrete Continuous Extreme Value (MDCEV) model of household activity generation that jointly predicts the activity participation decisions of all individuals in a household by activity purpose and the precise combination of individuals participating. The model is estimated on a sample obtained from the Post Census Regional Household Travel Survey conducted by the South California Association of Governments (SCAG) in the year 2000. A host of household, individual, and residential neighborhood accessibility measures are used as explanatory variables. The results reveal that, in addition to household and individual demographics, the built environment of the home zone also impacts the activity participation levels and durations of households. A validation exercise is undertaken to evaluate the ability of the proposed model to predict participation levels and durations. In addition to providing richness in behavioral detail, the model can be easily embedded in an activity-based microsimulation framework and is computationally efficient as it obviates the need for several hierarchical sub-models typically used in extant activity-based systems to generate activity patterns.
\end{abstract}

Keywords: Intrahousehold interactions, joint activity participation, multiple-discreteness, activity-based travel demand modeling 


\section{INTRODUCTION}

The emphasis of the activity-based approach to travel modeling is on activity participation and scheduling over a specified time period (usually a weekday in the U.S.), with travel being viewed as a derivative of out-of-home activity participation and scheduling decisions. While the detailed structures of activity-based models (ABMs) vary substantially, it is typical for ABMs to model "mandatory" activity decisions such as out-of-home work-related decisions (employed or not, duration of work, location of work, and timing of work) and education-related decisions (student or not, duration of study, location of study, and timing of study) as precursors to the generation of out-of-home non-work activity participations and the overall activity-travel schedules of individuals (including the scheduling of work and non-work episodes). Within the context of the generation of out-of-home non-work activity participation, while early activity-based travel studies ignored the interactions between individuals within a household (see, for example, Mannering et al., 1994, Lu and Pas, 1999), more recent studies and models have emphasized the need to explicitly consider such interactions and model joint activity participations within a household. This is motivated by several considerations. First, individuals within a household usually do not make their activity engagement decisions in isolation. As articulated by Gliebe and Koppelman (2002) and Kapur and Bhat (2007), an individual's activity participation decisions are likely to be dependent on other members of the household because of the possible sharing of household maintenance responsibilities, joint activity participation in discretionary activities, and pick-up/drop-off of household members with restricted mobility. These interactions in activity decisions across household members are important to consider to accurately predict activity-travel patterns. For instance, a husband's and wife's activity schedules are necessarily linked because of the spatial and temporal overlap when they both watch a movie or an opera at a theatre. In this regard, considering the husband's and wife's activity-travel patterns independently without maintaining the time-space linkage will necessarily result in less accurate activity travel pattern predictions for each one of them. Second, there is a certain level of rigidity in joint activity participations (since such participations necessitate the synchronization of the schedules of multiple individuals in time and space), because of which the responsiveness to transportation control measures such as pricing schemes may be less than what would be predicted if each individual were considered in isolation (Vovsha and Bradley, 2006, Timmermans and Zhang, 2009). Third, the activity-travel attributes of joint activity participations are systematically different from individual activity participations, even beyond the issue of rigidity in schedule. For instance, studies indicate that, in general, joint discretionary activity episode participations entail longer travel distances and longer participation durations relative to individual episode participations (Srinivasan and Bhat, 2006). Moreover, when a joint activity episode participation entails joint travel of some or all members participating jointly in the activity episode, the travel is more likely to be undertaken using larger and more spacious vehicles such as sports utility vehicles and vans, impacting the vehicle composition by type in the region, a key determinant of vehicular emissions (Konduri et al., 2011).

The emphasis on joint intrahousehold activity decisions has led to (or perhaps also been motivated by) another key substantive issue that has been receiving attention only more recently in the activity-based travel modeling literature. This pertains to the explicit modeling of children's activity decisions, and the inclusion of both adults' and children's activity-travel patterns within the travel demand modeling framework. After all, as Reisner (2003) indicates, parents spend considerable time and resources transporting children to and from after-school activities, while other studies have found that parents, especially mothers, make frequent stops 
on the commute to work and to, or from, non-work activities due to the need to escort children to activities (McGuckin and Nakamoto, 2004; see also Kato and Matsumoto, 2009 for extended discussions on this topic). The participation of children in activities, therefore, necessarily constrains adults' activity-travel patterns in important ways and may make an adult unresponsive to policy changes that attempt to modify travel mode, time of travel, or destination of travel. For instance, a parent driving a child to school during the morning peak is unlikely to shift away from the morning peak because of a congestion pricing strategy, even if the parent has a flexible work schedule. Similarly, in the case of a parent dropping a child off at soccer practice, it is the child's activity episode and its location that determines the temporal and spatial dimensions of the trip. In this context, Stefan and Hunt (2006) indicate that children as young as six years of age start developing their own independent activity participation needs that are then fulfilled by the logistical planning of their parents. Finally, the presence of children in the household can also increase joint activity participation in such activities as shopping, going to the park, walking together, and other social-recreational activities. Overall, modeling children's activity engagement (and the interactions between these engagements and those of adults) within activity-based travel model systems is an important pre-requisite for accurate travel forecasting in response to shifts in population demographics and land-use/transportation policies.

The discussion above motivates the current study. Specifically, we formulate and estimate a household-level activity pattern generation model that at once predicts, for a typical weekday, the independent and joint activity participation decisions of all individuals (adults and children) in a household, for all types of households, for all combinations of individuals participating in joint activity participations, and for all disaggregate-level activity purposes. To our knowledge, this is the first such comprehensive household-level pattern generation model in the literature. For example, almost all earlier studies in the intrahousehold interactions literature in both the economics and transportation fields have confined their theoretical and/or empirical attention to two adults in a household (see, for example, Lundberg, 2005, Apps and Rees, 2007, Cherchyne et al., 2011, Hertzberg, 2012, Zhang et al., 2005, Wang and Li, 2009; Kato and Matsumoto, 2009 in their empirical analysis, include a single child in addition to the two adults in the household). But such treatments of intrahousehold interactions are very limiting. Similarly, in terms of activity purposes, several earlier time use studies examine intrahousehold interactions exclusively in the context of a maintenance activity purpose category (see Vovsha et al., 2004, Srinivasan and Athuru, 2005, Wang and Li, 2009) or a discretionary activity purpose category (Yamamoto and Kitamura, 1999, Meloni et al., 2004, Srinivasan and Bhat, 2006, Kapur and Bhat, 2007). In the current paper, we consider both maintenance and discretionary activity purposes, with a disaggregate activity purpose classification as follows: (1) shopping (grocery shopping, clothes shopping, and window shopping), (2) non-shopping maintenance (ATM and other banking, purchasing gas, quick stop for coffee/newspaper, visiting post office, paying bills, and medical/doctor visits), which we will refer to simply as "maintenance" in the rest of this paper, (3) social (community meetings, political/civic event, public hearing, occasional volunteer work, church, temple and religious meeting), (4) entertainment (watching sports, going to the movies/opera, going dancing, and visiting a bar), (5) visiting friends and family, (6) active recreation (going to the gym, playing sports, biking, walking, and camping), (7) eat-out, (8) 
work-related, and (9) other (includes an "other" category as presented to respondents in the survey, as well as child-care and school-care activities). ${ }^{1}$

The rest of this paper is structured as follows. The next section provides an overview and economic basis of the analysis approach. Section 3 discusses the details of the modeling methodology. Section 4 provides an overview of the data source and the sample. Section 5 presents the empirical findings and model validation results. Finally, Section 6 concludes the paper by highlighting the contributions and findings of the study.

\section{THE ANALYSIS APPROACH}

\subsection{Overview}

There are several possible ways to model intrahousehold interactions in activity time-use decisions, including rule-based approaches (see Arentze and Timmermans, 2004, Miller and Roorda, 2003) and econometric approaches. One common econometric approach is based on the micro-economic time allocation framework (see Zhang and Fujiwara, 2006 and Kato and Matsumoto, 2009). In the class of such time allocation models, the Multiple Discrete Continuous Extreme Value (MDCEV) model proposed by Bhat (2008) is a simple and parsimonious way to accommodate intrahousehold interactions. It also is based on the notion that individuals determine the activity purposes to participate in, make decisions regarding with whom to participate in activities, and allocate time to different "activity purpose-with whom" combinations based on satiation and variety seeking behavior. Given these appealing behavioral characteristics of the MDCEV model, several recent studies have used the structure and its variants in the context of activity time use modeling (Habib and Miller, 2008, Xia et al., 2009, Paleti et al., 2010). However, these earlier applications of the MDCEV model have been individual-level models of time-use among multiple activity purposes, sometimes with aggregate representations of the "with whom" context of activity participations. They are fundamentally not household-level models of activity pattern generation. ${ }^{2}$ At the same time, the use of the MDCEV framework allows the choice of multiple alternatives at the same time, while traditional discrete choice frameworks allow only one alternative to be chosen. As a result, the number of composite alternatives (activity purpose - participating individual combinations) that need to be defined in the traditional discrete model choice set with $I$ out-of-home disaggregate activity purpose alternatives (all of which can be participated in individually or jointly in any person

\footnotetext{
${ }^{1}$ There is obviously some subjectivity in the activity purpose classification adopted here, though the overall consideration was to accommodate differences between the disaggregate activity purposes along such contextual dimensions as location of participation, physical intensity level, duration of participation, amount of structure in activity planning, and company type of participation (see Srinivasan and Bhat, 2005). Of course, the classification was also based on the activity purpose taxonomy used in the 2000 Southern California Association of Governments (SCAG) survey that provided the sample for the current analysis. Note also that we retain a "work-related" purpose as a maintenance activity as opposed to a mandatory work activity, and predict the work-related time allocation of each individual in the household if the individual is employed. In this regard, we will refer to work-related activity as a "non-work" activity in the current paper. Further, since no work-related activity participation time of any individual was joint with other individuals in the household (based on the survey data), we do not allow jointness in work-related activity participation among household members.

${ }^{2}$ On the other hand, the model developed in this paper is a household-level activity pattern generation model that determines time-use within a defined period (such as a weekday or an entire week) across all possible combinations of the members of a household (including individual members by themselves) and activity purposes. This includes the discrete choice of no participation in certain combinations and the continuous choice of time allocated to each combination in which there is participation.
} 
combination) and $P$ individuals in the household is $2^{I^{*}\left(2^{P}-1\right)}-1$, while the number of alternatives in the MDCEV model is only $I^{*}\left(2^{P}-1\right){ }^{3}$ Thus, consider the case of three disaggregate out-ofhome $(\mathrm{OH})$ activity purposes (say $A_{1}, A_{2}$, and $A_{3}$ ). For a single individual in the household, there are seven alternatives in the traditional model ( $A_{1}$ only, $A_{2}$ only, $A_{3}$ only, $\left.A_{1} A_{3}, A_{2} A_{3}, A_{2} A_{3}, A_{1} A_{2} A_{3}\right)$, but only three alternatives $\left(A_{1}, A_{2}\right.$, and $\left.A_{3}\right)$ in the MDCEV model. For two individuals $\left(P_{1}\right.$ and $\left.P_{2}\right)$ in the household and three activity purposes, the number of composite alternatives in the traditional model quickly mounts to 512, while the corresponding number is only nine $\left(A_{1} P_{1}, A_{1} P_{2}, A_{2} P_{1}, A_{2} P_{2}, A_{3} P_{1}, A_{3} P_{2}, A_{1} P_{1} P_{2}, A_{2} P_{1} P_{2}, A_{3} P_{1} P_{2}\right)$ in the MDCEV model (combinations of these alternatives may be chosen for participation in the MDCEV model, exhausting all the possible household activity purpose-participating individual combinations). The difference in the number of alternatives becomes stark as the number of individuals increases. With just three household members, the number of alternatives in the choice set for the traditional discrete choice model explodes to over 2 million, while the corresponding number is only 22 in the MDCEV set-up.

\subsection{Economic Basis}

As in most models of intrahousehold time-use based on micro-economic theory (see, for example, Kato and Matsumoto, 2009 and Zhang et al., 2005), we use the time components as the decision variables in the direct utility function. In terms of capturing household interactions, earlier economic models have devoted attention on the process and representation of moving from individual utility functions to household utility functions. This is still a developing field, and there is little consensus on which theoretical model of group utility formation (from individual utilities) is most appropriate to a given group context (in the current case, the "group" is a household). Further, as observed by Cherchyne et al. (2011), group decision processes are not only likely to be affected by strictly individual-based preference (or utility) functions (as is usually considered when moving from individual to group functions through combining strictly individual utility functions), but also likely to be situation-dependent based on the composition of the group and other relevant environmental attributes characterizing the household choice situation. Thus, for example, the intrinsic value that an individual places on shopping activity may itself be a function of the size and characteristics of the group with whom she or he is considering going shopping. Besides, there is typically a complex interplay of participation in the multi-step decision process leading up to a joint activity that can be difficult to represent in frameworks that simply combine individual utilities in specific ways. So, as in Zhang et al. (2009), we develop our random utility model of household interactions at the level of the discrete alternatives of activity purpose-party combinations in a household (in contrast, and as alluded to earlier, traditional approaches of group decision-making are developed at the level of individuals). In addition to addressing the issues discussed above, our approach of group decision-making at the level of the discrete alternatives has at least three other advantages over

\footnotetext{
${ }^{3}$ Of course, these formulas will need to be adjusted in minor ways to accommodate for the fact that there is no jointness in work-related activity, and that this activity purpose applies only to employed individuals in the household. But the formulas provide a clear magnitude effect assuming there were no restrictions on any of the $I$ activity purposes. Also, technically speaking, there needs to be an additional alternative in both the discrete choice and the MDCEV structures that corresponds to all individuals in the household staying at home for the entire day. However, as will be discussed in the next section, we consider this alternative outside the MDCEV framework.
} 
more traditional approaches of group decision-making such as in, for example, Zhang et al. (2005) and Kato and Matsumoto (2009). First, our approach explicitly considers the decreasing marginal valuation (or satiation) in time invested in each discrete alternative of activity purpose and participating individuals, as opposed to traditional approaches that only consider satiation within an individual for each activity purpose. Just as the idea of satiation within an individual for a specific activity purpose may be motivated from Iso-Ahola's (1983) theory that the diversification of participation in different types of activities is a natural consequence of a socialpsychological need for optimal arousal based on stability (psychological security) as well as change (novelty), it is only reasonable that satiation is present in terms of time investment in each discrete alternative of activity purpose and participating individuals. Indeed, Sener and Bhat (2007), Kapur and Bhat (2007), and Habib et al. (2008) all clearly demonstrate the presence of such satiation effects by activity purpose-participating individual combinations. Second, the formulation at the level of the discrete alternatives immediately obviates the need for constraints that maintain equality in time investments across individuals involved in joint activities. In the traditional approach, as the number of individuals increases, the number of such constraints explodes quickly, making things difficult in both model estimation and forecasting. It is no surprise, therefore, that almost all earlier household interaction empirical efforts in both the economics and travel demand field have confined their attention to a couple household or a couple household with one child. Third, by defining utility for each discrete alternative of activity purpose-participating individual combination, and then aggregating over the discrete alternatives to obtain a total household utility, we are effectively able to allow discrete alternative-specific weights that relax the assumption that the weight (or influence or power) that an individual exerts is independent of the group characteristics. For instance, it is possible that the "say" that a husband has relative to a wife in time investment in an activity that they may pursue together would be quite different from the "say" that the husband will have (or wants to exert) relative to the wife in time investment in an activity that is also pursued with a child.

Given our approach of modeling group decision-making at the level of discrete alternatives, there is still the issue of developing the sub-utility function for each discrete alternative and moving from there to the total household utility function. As in the case of moving from individual utility functions to household utility functions where individual subutilities are 'aggregated", our task is to specify the discrete alternative sub-utility function and move from there to the total household utility function. For the sub-utility function, we maintain the following specification as proposed by Bhat (2008):

$U_{q k}\left(t_{q k}\right)=\gamma_{q k} \psi_{q k} \ln \left(\frac{t_{q k}}{\gamma_{q k}}+1\right)$

where $t_{q k}$ is the time in discrete alternative $k$ (for activity purpose-participating individual combination) for household $q$, and the $\psi_{q k}\left(\psi_{q k}>0\right)$ term represents the marginal utility of one unit of time investment in alternative $k$ for household $q$ at the point of zero time investment for the alternative. It controls the discrete choice participation decision in alternative $k$ and is usually referred to as the baseline utility or baseline preference for alternative $k \cdot \gamma_{q k}\left(\gamma_{q k}>0\right)$ is a translation parameter which serves three purposes - (1) it plays the role of satiation parameter that reduces the marginal utility with increasing consumption of the alternative $k$; higher values of $\gamma_{q k}$ imply lower satiation effects, (2) it allows the presence of corner solutions or zero 
consumptions of alternatives, and (3) it plays the role of the relative weight for discrete alternative $k$ when the sub-utilities are aggregated to form the household utility function. Note that the functional form in (1) is more general than those used in the past for sub-utility functions. For example, many earlier studies, such as Kato and Matsumo (2009), assume a priori that $\gamma_{q k}=1$ (for all $q$ and $k$ ), which constrains the satiation effect to be the same across all alternatives and all households. Our specification allows the data to determine the level of satiation, and also allows varying satiation across alternatives and households (see Bhat, 2008 for a detailed explanation). In terms of relative weights, as $\gamma_{q k}$ increases, there is higher time investment in the alternative $k$ by the household.

Equation (1) is a valid sub-utility function (Bhat, 2008). The baseline utility term $\psi_{q k}$ may be written as a multiplicative combination of baseline utility terms associated with (1) the purpose $l_{k}$ corresponding to discrete alternative $k$, (2) the set $S_{q k}$ of individuals characterizing the alternative $k$, (3) household characteristics, and (4) combinations of purpose, household, and individual interaction variables. Further, we also include a stochastic term to recognize the effect of all unobserved factors that may influence the overall utility of alternative $k$. Formally, and corresponding to the terms just mentioned, we write:

$$
\psi_{q k}=\psi_{l_{k}} \times\left(\prod_{p \in S_{q k}} \psi_{p}\right) \times \psi_{q} \times \tilde{\psi}_{q k} \times e^{\varepsilon_{q k}}
$$

The multiplicative specification above takes into account the baseline utilities of individual preferences, which can include the income of individual members (to capture power roles), the gender of individual members (to capture gender roles), interactions of gender and income (for example, to capture tempering of gender roles based on income), as well as altruism concepts through the interaction baseline utility component $\tilde{\psi}_{q k}$. Thus, our model may be viewed as a Samuelson-type (Samuelson, 1956) Generalized Household Welfare Function (GHWF) interaction model applied to the baseline utilities at the level of the discrete alternative $k{ }^{4}$ In terms of utility function forms, the household baseline utility for the discrete alternative $k$ takes the Nash-type form. ${ }^{5}$ An important difference from earlier studies is that we are writing the baseline utility (as opposed to total utility) for the discrete alternative in the Nash product form. This is consistent with the notion that household interactions in activity participation involve

\footnotetext{
${ }^{4}$ See App and Rees (2007), Del Boca and Flinn (2012) and Kato and Matsumoto (2009), who discuss the many types of intrahousehold resource allocation models, including Becker's (1965) unitary model and extensions, noncooperative and cooperative bargaining models (including Nash bargaining models), Chiappori's (1988) collective models that include altruism, and Samuelson's Generalized Household Welfare Function (GHWF). The paper by Apps and Rees is of particular relevance here. These authors show how the GHWF approach is a very general formulation that can accommodate elements of conflict and cooperation in household decision-making through the appropriate specification of exogenous variables, as we have also discussed in the main text. The essential position of the GHWF formulation is that many different types of processes are likely to be at work in intrahousehold decision-making, and it is not necessary that the researcher should adopt one specific process as being the (only) basis for decision-making. Rather, there is value in "abstracting from the process by which an allocation or preference ordering is reached", especially when we are still nowhere close to identifying the specific process (or combination of processes) at work (see Lundberg, 2005 and Del Boca and Flinn, 2012), and adopting a general "reduced-form" function that nonetheless captures elements of several different processes at once.

${ }^{5}$ Zhang et al. (2009) provide a good review of utility forms, and discusses the Nash utility form as a specific case of the iso-elastic utility function form.
} 
both a discrete component (whether or not to participate in a specific alternative) as well as a continuous component (the amount of time to invest). The discrete decision is controlled by the baseline utility that a household attributes to each possible alternative, which implies that one needs to first form a household-level baseline utility for each alternative. The household-level baseline for each alternative, combined with the household-level weight for each alternative $\left(\gamma_{q k}\right)$, determines time investment (similar to $\psi_{q k}$, we may also write $\gamma_{q k}$ as a product of purpose, individual, household, and combination components). Finally, writing each non-stochastic baseline component for discrete alternative $k$ in Equation (2) as the exponent of a linear combination of relevant variables, Equation (2) may be written equivalently and simply as:

$\psi_{q k}=\exp \left(\beta^{\prime} z_{q k}+\varepsilon_{q k}\right)$

where $z_{q k}$ is a vector of exogenous determinants (including a constant) specific to alternative $k$ (including exogenous variables relevant to the purpose, individuals, household, and interaction variables relevant to alternative $k$ ). $\gamma_{q k}$ may be similarly specified, though we will continue writing it as such for presentation simplicity.

Defining the vector $\boldsymbol{t}_{\boldsymbol{q}}=\left(t_{q 1}, t_{q 2}, \ldots, t_{q K}\right)$, the total GHWF (or total household utility function) is formulated as the sum of the sub-utility GHWFs for the discrete alternatives:

$U_{q}\left(\boldsymbol{t}_{\boldsymbol{q}}\right)=\sum_{k} \gamma_{q k} \exp \left(\beta^{\prime} z_{k}+\varepsilon_{k}\right) \ln \left(\frac{t_{q k}}{\gamma_{q k}}+1\right)$

\section{MODEL STRUCTURE AND OPERATIONALIZATION}

In this section, we present an overview of the MDCEV model structure, which is based off the total GHWF in Equation (4). The reader is referred to Bhat (2005) and Bhat (2008) for the details of the MDCEV model structure. Also, in this section, we will suppress the index for households $q$ and present the structure for a single household with $K$ out-of-home $(\mathrm{OH})$ "activity purposeparticipating individuals” combination discrete alternatives (for ease in presentation, we will refer to the $\mathrm{OH}$ activity purpose-participating individual combination alternatives simply as activity alternatives in the rest of this paper). Note that, in reality, $K$ will vary across households based on the number of individuals in the household. Let $t_{k}$ be the amount of time invested in activity alternative $k(k=1,2, \ldots, K)$ over the course of the weekday, and let $\sum_{k=1}^{K} t_{k}=T$, where $T$ represents the total time across all household members that is available for $\mathrm{OH}$ non-work activity participation.

An important point is in order here. We are not including the household-level activity alternative that corresponds to all individuals staying at home for the entire day in the way we have defined our $K$ alternatives. This is because the duration for this alternative can be as high as $1440 \times Q$, where $Q$ is the number of individuals in the household. This very large duration for a single alternative leads to difficulties when estimating the non-linear utility functions in the MDCEV model. Thus, we first estimate a simple binary choice model to predict whether or not a household has any $\mathrm{OH}$ non-work participation at all (across all its household members), based on household and individual characteristics (such as age of adults, presence of children, family 
structure, commute times, work characteristics of individuals, etc.). ${ }^{6}$ Then, we only consider those households that have a non-zero OH work participation time in the MDCEV model, which also then does not have the alternative corresponding to all individuals staying at home. ${ }^{7}$ This way of inclusion of households implies that each household must choose at least one alternative for participation in the MDCEV model from the $K$ activity alternatives (of course, this does not preclude the possibility that specific individuals in the household will have no $\mathrm{OH}$ activity during the day; for instance, if all the alternatives involving individual $q(q=1,2, \ldots, Q)$ have no time allocation, it implies that individual $q$ stays at home the entire day).

For model estimation, the MDCEV model still, however, needs the value of $T$, corresponding to the total time available for $\mathrm{OH}$ non-work activity participation. To obtain this, we first remove the work duration of each individual $q(q=1,2, \ldots, Q)$ in the household from the total duration in a day to obtain the available non-work time (in minutes) as follows: NWTIME ${ }_{q}=1440-W T I M E_{q}$ (in minutes). Next, the total non-work time at the household level may be computed as HNWTIME $=\sum_{q=1}^{Q} N W T I M E_{q}$. However, HNWTIME includes travel times to $\mathrm{OH}$ activities as well as the in-home times (including sleep times) of individuals. So, we need to remove these times from HNWTIME (note that travel times are determined only later in the scheduling phase, and are not available at the activity generation phase). We proceed by estimating a fractional split model (see Sivakumar and Bhat, 2002 for details of this model structure) for each household, so that we are able to split HNWTIMEinto at-home time, travel time, and out-of-home non-work activity time $(T)$. In this paper, we do not provide details of the fractional split model, and focus primarily on the MDCEV model and its results.

From the analyst's perspective, households are maximizing random utility $U(t)$ subject to the time budget constraint that $\sum_{k} t_{k}=T$. Assuming that the error terms $\varepsilon_{k}(k=1,2, \ldots, K)$ are independent and identically distributed across alternatives with a type 1 extreme value distribution, ${ }^{8}$ the probability that household allocates time to the first $M$ of the $K$ alternatives (for duration $t_{1}^{*}$ in the first alternative, $t_{2}^{*}$ in the second, ... $t_{M}^{*}$ in the $M^{\text {th }}$ alternative) is given by (see Bhat, 2008 for a detailed derivation of this simple result):

$$
\begin{aligned}
& P\left(t_{1}^{*}, t_{2}^{*}, t_{3}^{*}, \ldots, t_{M}^{*}, 0,0, \ldots, 0\right) \\
& =\left[\prod_{i=1}^{M} c_{i}\right]\left[\sum_{i=1}^{M} \frac{1}{c_{i}}\right]\left[\frac{\prod_{i=1}^{M} e^{V_{i}}}{\left(\sum_{k=1}^{K} e^{V_{k}}\right)^{M}}\right](M-1) !
\end{aligned}
$$

\footnotetext{
${ }^{6}$ In the SCAG survey sample used in the empirical estimation of the current paper, $23.4 \%$ of households did not have any non-work activity participation at all during the weekday.

${ }^{7}$ This procedure may be viewed as a form of two-stage allocation, in which the household and its members can be thought of as optimally allocating total available non-work time between in-home and total $\mathrm{OH}$ time in the first stage, followed by the allocation of total $\mathrm{OH}$ time across the discrete alternatives.

${ }^{8}$ While we use the simple MDCEV model in the current empirical context, it is possible to extend the MDCEV framework to accommodate more flexible error structures using generalized versions of the MDCEV models (please see Pinjari and Bhat, 2010a and Bhat et al., 2006 for such applications in the time-use context).
} 
where $c_{k}=\left(\frac{1}{t_{k}^{*}+\gamma_{k}}\right)$ and $V_{k}=\beta^{\prime} z_{k}-\ln \left(\frac{t_{k}}{\gamma_{k}}+1\right)(k=1,2,3, \ldots, K)$.

\section{DATA}

The data for our analysis is drawn from the 2000 Post Census Regional Household Travel Survey conducted by the South California Association of Governments (SCAG), which is the metropolitan planning organization (MPO) of the six-county Los Angeles region of California.

\subsection{Determination of Joint Activity Participation and Associated Daily Duration}

The survey data obtained point information or closest cross-street intersection information for all locations (home locations, work locations, and all other activity locations) of each trip end of each individual in the survey. This was translated by SCAG to spatial coordinates, and served as the basis to determine joint activity participation decisions among household members. Specifically, the trip end information was converted to activity episode information, and each activity episode was assigned as an independent episode or a joint episode based on examining the reported activity locations of all household members. If the reported locations of activity episodes were the same across two or more household members, and the time of day of the episode start was reported within a "buffer-window" of ten minutes, the corresponding episode was tagged as a possible joint activity episode. Next, the activity purpose reported by each individual for each tagged episode was examined. If the activity purposes reported by the involved individuals were the same (type A episode), or if one or more of the involved individuals reported the activity purpose of participation as "accompanying another individual" with the other involved individuals reporting the same activity purpose (type B episode), the tagged episode was designated as a joint activity episode. The activity purpose for the type A episode is straightforward, while the activity purpose for the type B episode corresponds to the activity purpose of the individual(s) who reported a purpose other than "accompanying another individual" (Kang and Scott, 2008 use a similar method to identify joint activities). Finally, the durations of episodes were aggregated by purpose and participating individuals to obtain the weekday durations, and served as the dependent variables of the MDCEV model.

\subsection{Sample Formation}

As indicated in Section 1, the activity purposes from the survey were categorized into nine different purposes. Of these nine purposes, no joint participation was observed for work-related activity. Thus, we allow joint activity participation in eight purposes, and only independent participation in the work-related purpose category. The number of individuals in the household varied from one to nine individuals. However, households of size five or less constituted well over $97 \%$ of all households. For these households, the maximum number of alternatives is 253 $\left(=\left[\left(2^{5}-1\right) \times 8\right]\right.$ (alternatives corresponding to 8 activity purposes in which joint activities are allowed) + [5] (alternatives corresponding to work-related activity purpose in which joint activities are not allowed)). In estimation, we focus on these households, because of the reasonable number of alternatives. However, once the model is estimated with 253 alternatives, it can be applied to households of any size because of the manner in which the model is specified.

The final sample for estimation included 8900 households (with less than or equal to five household members). These correspond to households that had at least one non-work out-ofhome $(\mathrm{OH})$ activity participation during the course of the day. The household size distribution of 
these households was as follows: 1 individual (30.8\%), 2 individuals (36.6\%), 3 individuals (14.5\%), 4 individuals (12.7\%), and 5 individual (5.5\%).

\subsection{Construction of Accessibility Measures}

In addition to the 2000 SCAG survey data set, several other secondary data sets were used to obtain residential neighborhood accessibility measures that may influence household-level activity participation behavior. The secondary data sources included geo-coded block group and block data within the SCAG region obtained from Census website, roadway network skims from SCAG, the employment data from the Census Transportation Planning Package (CTPP) and Dun \& Bradstreet (D\&B), and the 2000 Public-Use Microdata Samples (PUMS) from Census 2000 and the marginal distributions (population and household summary tables) from SCAG.

Two types of accessibility measures were constructed in the current analysis. The first set of accessibility measures are opportunity-based indicators which measure the number of activity opportunities by twelve different industry types that can be reached within 10 minutes (on the highway network) from the centroid of the home block during the morning peak period (6am to 9am). The reader is referred to Chen et al. (2011) for details. These may be viewed as local accessibility measures. The second set of accessibility indicators correspond to Hansen type zonal-level regional accessibility measures (Bhat and Guo, 2007), which take the following form:

$A c c_{i, \tilde{t}}=\frac{1}{N} \sum_{j=1}^{N}\left(\frac{\text { Size Measure }_{\mathrm{j}}}{\text { Impedance }_{\mathrm{ij}, \tilde{\mathrm{t}}}}\right)$, where $i$ is the index for zone, $\tilde{t}$ is the index for the time period, and $N$ is the total number of zones in the study region (four time periods were used in our analysis: AM peak (6:30 am-9 am), midday (9 am-4 pm), PM peak (4 pm-6:30 pm), and evening (6:30 pm-6:30am)). Impedance ${ }_{\mathrm{ij}, \tilde{\mathrm{t}}}$ is the composite impedance measure of travel between zones $i$ and $j$ at time period $\tilde{t}$ and is obtained as: Impedance $_{\mathrm{ij}, \tilde{\mathrm{t}}}=I V T T_{i j, \tilde{t}}+\lambda \operatorname{Cost}_{i j, \tilde{t}}$, where $I V T T_{i j, \tilde{t}}$ and $\operatorname{Cost}_{i j, \tilde{t}}$ are the auto travel time (in minutes) and auto travel cost (in cents), respectively, between zones $i$ and $j$ in time period $\tilde{t}$, and $\lambda$ is the inverse of the money value of travel time. We used $\lambda=0.0992$ in the current study, which corresponds to about $\$ 6$ per hour of implied money value of travel time. For the zonal size measure in the accessibility formulation, we considered four variables -- retail employment, retail and service employment, total employment, and population. Finally, the time period-specific accessibility measures computed as discussed above were weighted by the durations of each time period, and a composite daily accessibility measure (for each size measure) was computed for each traffic analysis zone, and appended to sample households based on the residence TAZs of households. ${ }^{9}$

\subsection{Descriptive Analysis}

Table 1 presents the descriptive statistics of household-level activity participation decisions in the final estimation dataset, including the (1) percentage of households in which no individual participates at all during the day in the row activity purpose (the first numeric column), (2) percentage of households (from among those who participate in the row activity purpose) with only single individual (or independent) activity participations over the course of the day (the

\footnotetext{
${ }^{9}$ Future studies would benefit from exploring alternate forms of accessibility as well as the consideration of transit and non-motorized mode network skims (in addition to the highway network skims used here). The transit and nonmotorized mode skims were not considered in our study due to data-related quality limitations.
} 
second numeric column), (3) percentage of households (from among those who participate in the row activity purpose) with joint activity participations of two or more individuals (the third through sixth columns; note that the sum of the second through sixth numeric columns is $100 \%$ for each row), (4) the mean duration of daily time investment among households who participate in each activity purpose in the overall, and by individual or joint activity engagement (the seventh and eight columns), and (5) the percentage of households participating in each activity purpose who solely participate in that activity and who also participate in other activity purposes (the last two columns; the sum of these last two columns is $100 \%$ for each row).

The descriptive statistics in the first numeric column of Table 1 reveal that households (i.e., across all individuals in the household) are most unlikely during the weekday to participate in relatively discretionary activities (social, entertainment, visiting, active recreation), workrelated activity, and the catch-all "other" activity purpose. The most likely participation is in the maintenance-oriented purposes of shopping and other maintenance activities. Among households who participate in each activity purpose, not surprisingly, independent participations are the most common (see the second numeric column; note, however, that the statistics here are not for episodes of participation, but for daily participations). Independent participations are particularly frequent for the maintenance, active recreation, and visiting activity purposes (of course, all work-related participations in the day were pursued alone). On the other hand, shopping, entertainment, eat-out, and "other" activities (relative to the remaining activity purposes) are more likely to be pursued jointly with other household members (see the higher percentages corresponding to these purposes in the third through sixth numeric columns of the table). Also, as expected, the most frequent type of joint activity participation for all activity purposes is with two participating individuals in the household (though the number of individuals participating jointly is also a function of the number of individuals in the household).

The "mean duration of daily time investment among households who participate" column shows the high overall daily time investments of participating households in entertainment and work-related purposes. The purposes with the least time investments are the shopping and eat-out purposes, with each having a mean duration of less than an hour. Also interesting to note is the difference in daily time durations based on independent (that is, single individual) versus joint (that is, multiple individual) participation. While there are no substantial differences for the shopping, maintenance, and eat-out activity purposes, the daily time investments on joint participation for the relatively discretionary purposes (social, entertainment, visiting, and "other") are lower than for independent participations in these purposes.

The final two columns in Table 1 indicate the split between single activity purpose participation (i.e., household participation in only one activity purpose category) and multiple activity purpose participation (i.e., household participation in multiple activity purpose categories) for each activity purpose. Thus, for instance, $14.7 \%$ of households who participate in shopping activity during the course of the day participate only in this activity during the weekday, while $85.3 \%$ of households who participate in shopping activity also participate in other activity purposes (note that these participations refer to the participations across all individuals in the household). Clearly, this indicates the variety of activity purposes in which households participate over the course of a weekday, and reinforces the use of the MDCEV model for modeling household-level activity participation. 


\section{EMPIRICAL RESULTS}

The model estimation process was guided by the findings of earlier studies, intuitiveness, and parsimony considerations. In the most general way of specifying an MDCEV model, the number of coefficients for each covariate in the $\mathbf{z}_{k}$ independent variable vector would be of the order of the number of alternatives, which is 253 for a household with five individuals. However, this way of specifying alternative-specific coefficients is not efficient, and also not behaviorally sound because the specification should accommodate the specific characteristics of the household as a whole and each individual in the household (rather than "label" each member as A or B or C). Besides, a full "labeling" approach of estimation will not also work because of the few households that have four and five individuals. In addition, the approach is not amenable to application in forecasting for households that have more than five individuals.

In our empirical analysis, the baseline preference utility of the independent (single person participating) activity alternatives for any household is specified as a function of household, individual characteristics, and residential neighborhood accessibility, while the utility of joint (multiple individuals participating) activity alternatives is specified as a function of household, combination of individual characteristics constituting the alternative (for example, whether the alternative includes a child or not), and residential variables. In general, covariates may impact the utilities of the "joint activity purpose-participating individual" activity alternatives through (1) the "activity purpose" dimension, (2) the "participating individuals" dimension, (3) dual, but independent, effects on the "activity purpose" and the "participating individuals" dimensions, and/or (4) an interaction effect on the "activity purpose" and the "participating individuals" dimensions. We consider all of these possible effects on the baseline utilities of alternatives in developing a parsimonious specification. In our presentation of results, we will explicitly identify the "base" category for the first, second, and third groups of covariate effects. For the fourth group of covariate effects, the "base" category will be implicit from the alternatives not listed (it is not space-efficient to list all the base alternatives in this case).

Table 2 presents the model estimation results of the best MDCEV model specification obtained in our study. The model results are discussed under five sections - effects of household demographics (Section 5.1), effects of individual characteristics (Section 5.2), effects of accessibility measures (Section 5.3), baseline preference constants and translation parameters (Section 5.4), and model fit and validation (Section 5.5).

\subsection{Effects of Household Demographics}

The effects of the first two variables in Table 2 under "household demographics" indicate that households with more children (aged less than or equal to 15 years), relative to households with fewer children, are very likely to participate in the "Other" activity purpose. This is not surprising because, by definition, the "Other" activity purpose involves child care, school care, and after school care activities. Also, these households are less inclined toward eat-out and shopping activity participation on a typical weekday, perhaps because of a preference to undertake these activities more leisurely during the weekends without the time pressures of work/school and child-care responsibilities of the typical weekday (Gliebe and Koppelman, 2005). However, it is interesting that such time pressures do not appear to extend to active recreation activities when school going children are present. Indeed, the presence of school going children increases the baseline preference for these activity purposes, perhaps because of schoolrelated active recreation of children as well because children can drive the activity recreation participation decisions of the household (see, Mallett and McGuckin, 2000, Stefan and Hunt, 
2006, and Rajagopalan et al., 2009). Another point to note is that households with more nonschool going children (a proxy for very young children in the household) are less likely to partake in social activities during a typical weekday (relative to households with fewer nonschool going children).

As expected, and as also observed by Habib and Miller (2008), households with more senior adults (aged more than 65 years), relative to households with fewer senior adults, have a predisposition to partake in activities other than work-related activity. This is particularly so for social activities such as community meetings, voluntary activities, and religious events, which provide the opportunity for senior adults to connect with other individuals and forge new social relationships. The effects of high household income get manifested in the generally higher likelihood to engage in work-related and active recreation activities relative to other non-work activities (unfortunately, individual incomes were not available to capture additional powerbased effects). The higher levels of participation in work-related activity is perhaps a sign of the higher job responsibilities and workaholic tendencies among individuals in such households, while the higher participation levels in active recreation is likely a result of financial affordability to access gyms and health clubs. The latter result that individuals in higher income households are more likely than individuals in low (and even moderate) income households to pursue active recreation is a recurring theme in the physical activity literature (see Bennett et al., 2007). There have been suggestions that, while active recreation can be pursued in and around neighborhoods without much financial implications, the quality of the environment in which low income households reside may have a bearing on their low active recreation tendencies. As stated by Bennett et al. (2007), "residing in a neighborhood that is perceived to be unsafe at night is a barrier to regular physical activity among individuals, especially women, living in urban lowincome housing. Feeling unsafe may also diminish confidence in the ability to be more physically active.” Table 2 also shows another effect of high household income, which is that non-work activity participations in such households are likely to be pursued solo. Finally, in the class of household demographics, the effects of the number of vehicles in the household mirrors the effects of high household income with one important difference. Households with a higher number of vehicles, but not in the high income group ( $>100 \mathrm{~K}$ per year), have a tendency to participate more in visiting activities compared to those with a lower number of vehicles but in the high income group. This is suggestive of conscious lifestyle choices and lifestyle preferences; for instance, households with high income and low number of motorized vehicles may be predisposed to a physically active lifestyle with lower preference for visiting activities.

\subsection{Effects of Individual Characteristics}

In this class of variables, we include the effects of individual characteristics such as work schedules and demographics. These variables get introduced in the form of representations of individuals who constitute an activity alternative. Thus, for example, variables for work end time and work duration are created for each "activity purpose-participating individual" combination alternative as the latest work end time and maximum work duration among all participating individuals in that combination alternative. If an alternative corresponds to solo (independent) participation in a certain activity type for a certain individual, then (and only then) does the latest work end time variable for the alternative collapse to the work end time of the individual.

The results for work end time suggest that activity alternatives involving individuals with late work end times will generally not be pursued, which is reasonable because the post-work time window for non-work activities gets squeezed (Rajagopalan et al., 2009). However, the 
table also shows that this time window constraint is not very active for maintenance, visiting, and eat-out activities, perhaps because these activities do not have a rigid schedule and may be pursued even late at night (unlike, for example, entertainment events and other social events that may start at a certain time in the evening). Work duration also has an influence on the preferences for activity alternatives. Specifically, it is not likely that shopping, maintenance, social, and active recreation participations will be pursued by (or with) individuals who work long hours, though eat-out and work-related participations are likely to increase for (or with) individuals working long hours. The increased work-related participation may simply be a reflection of the "workaholic" tendency that led to a long work duration in the first place (note that work-related participations are never pursued jointly).

The "number of children among participating people" variable has a negative sign, indicating that children are almost always going to be accompanied by an adult individual, regardless of activity purpose. Other results indicate that children, when present in the household, are likely to be involved in joint activities for shopping, social, and entertainment, but are unlikely to be companions in joint maintenance activity pursuits (such as when paying the bills or banking). The next variable in the table suggests that those adults who have the responsibility of dropping off/picking up children at/from school are also likely to pursue shopping, maintenance, and eat-out activities by themselves or with other individuals in the household; these adults are unlikely to be involved in work-related activities. The introduction of this variable captures the effects of being the primary child-care and household maintenance "point person" (note that the assignment of who drops off/picks up children at/from school is determined prior to the application of the proposed MDCEV model, and that assignment is based on individual demographics as well as work-related characteristics).

Finally, the results show that a child and a woman adult are more likely to participate together in activities of all purposes, either by themselves or with other household members. This is consistent with the findings of several earlier studies (see, for example, Gliebe and Koppelman, 2005) that women tend to be more responsible for the activities of children.

\subsection{Accessibility Measures}

In the current empirical context, none of the accessibility measures in the first set of opportunitybased accessibility measures (see Section 4.3) turned out to be statistically significant. In the second group of Hansen-type accessibility indicators, two measures (one corresponding to retail plus service employment as the size measure and another corresponding to population as the size measure) have significant impacts. Specifically, we found that households residing in zones with high retail and service employment accessibility are more likely to invest time in active recreation, eat-out, entertainment, shopping, and maintenance activities relative to work-related activities. This is a direct consequence of increased activity participation opportunities, and is consistent with the results from several earlier studies of the effects of the built environment on activity generation (see, for instance, Pinjari et al., 2009, Cervero and Duncan, 2003, and Fan and Khattak, 2009). On the contrary, households in zones with high population accessibility are less likely to participate in active recreation, eat-out, entertainment, shopping, and maintenance activities, perhaps because zones with high population accessibility are not rich in land-use mix, thus inhibiting activity participation. 


\subsection{Baseline Preference Constants and Satiation Parameters}

The baseline constants for different activity purposes, in general, capture generic tendencies to participate in different activity purposes. However, in our specification with many continuous variables, the baseline constants do not have a straightforward interpretation and serve as overall adjustors to fit the data best given the exogenous variables. We do not present the baseline constants here due to space constraints.

As discussed earlier in the methodology section, a higher value for the translation parameter $\gamma_{k}$ for alternative $k$ implies higher preference and less satiation (i.e., higher durations of time investment conditional on participation) in alternative $k$. The translation parameter estimates (not shown in Table 2 to conserve on space) indicated substantial variation in the translation parameters across the activity purpose categories and across the "number of participating individuals" categories. These variations are statistically significant based on the estimated standard errors. Also, the satiation parameters were consistent with the high mean value of participation duration in entertainment, and the low mean values of participation duration in maintenance, shopping, and eat-out activities (see Table 1).

\subsection{Model Fit and Validation}

The log-likelihood value at convergence for the model in Table 2 is -136922.89 , while the loglikelihood value for the naïve model with only the baseline preference constants and the translation parameters is 139023.13. The log-likelihood ratio test statistic value for the comparison between our model specification and the naïve model is 4200.54, which is much higher than the critical chi-squared value with 72 degrees of freedom at any level of significance. This is clear evidence of the contribution of explanatory variables in predicting household-level activity participations and durations. We also undertook an aggregate validation exercise of the final MDCEV model by comparing the predictions from the model (as obtained using the forecasting algorithm of Pinjari and Bhat, 2010b) to the observed participation levels and durations in the estimation sample. For presentation ease, we undertook this exercise at the level of the "activity purpose-number of participating individuals" combinations rather than at the more disaggregate-level model predictions of the activity purpose and the precise companionship arrangement.

The results of the validation exercise are presented in Table 3, which is in the same format as Table 1. The predictions from the model are provided first, followed by the actual corresponding estimation sample values in parenthesis. The MDCEV model does very well in predicting the observed participation levels in each "activity purpose-number of participating individuals" category.

\section{CONCLUSION}

This study has formulated and estimated a household-level activity pattern generation model that at once predicts, for a typical weekday, the independent and joint activity participation decisions of all individuals (adults and children) in a household, for all types of households, for all combinations of individuals participating in joint activity participations, and for all disaggregate-level activity purposes. The model uses a host of household, individual, and residential neighborhood accessibility measures as inputs.

The household level activity pattern generator module of this paper is embedded within the activity-travel pattern generator and scheduler component of SimAGENT. In addition to providing richness in behavioral detail, the model contributes to the run speed of SimAGENT by 
obviating the need for several hierarchical sub-models typically used in extant activity-based systems to generate activity patterns. The forecasting algorithm recently proposed by Pinjari and Bhat (2010b) is used to predict household-level participation levels and durations, which then informs the scheduling of activity episodes and travel for each household member. The reader is referred to Goulias et al. 2012 for a complete and detailed discussion of all the components of SimAGENT. The empirical results are intuitive and insightful, and illustrate the behavioral richness of the MDCEV formulation. The validation exercise undertaken in the study also shows that the MDCEV predictions match closely with the observed data. Ongoing and future efforts will continue to refine and update the model using new survey data, undertake extensive sensitivity testing and validation exercises, and employs the proposed model as part of the larger SimAGENT model system to assess a variety of policy scenarios in terms of behavioral changes, traffic congestion, and GHG emissions. Of course, going beyond households to model interactions in activity participation and scheduling remains an interesting area for further research (see Ronald, 2012 and Sener et al., 2011 for examples of recent efforts in this direction).

\section{ACKNOWLEDGEMENTS}

This research was undertaken as part of a Southern California Association of Governments (SCAG) project for the development of an activity based travel demand model for the Southern California region. The authors appreciate Lisa Macias's help in typesetting and formatting this document. Three anonymous reviewers provided useful comments on the earlier paper version. 


\section{REFERENCES}

Apps P, Rees R (2007) Cooperative household models. Discussion paper 3127, Institute for the Study of Labor (IZA), Bonn, Germany.

Arentze TA, Timmermans HJP (2004) A learning-based transportation oriented simulation system. Transportation Research Part B 38(7): 613-633.

Becker G (1965) A theory of the allocation of time. Economic Journal 75(299): 493-517.

Bennett GG, McNeill LH, Wolin KY, Duncan DT, Puleo E, Emmons KM (2007) Safe to walk? Neighborhood safety and physical activity among public housing residents. PLoSMedicine, 4(10), e306.

Bhat CR (2005) A multiple-discrete continuous extreme value model: formulation and application to discretionary time-use decisions. Transportation Research Part B 39(8): 679707.

Bhat CR (2008) The multiple discrete-continuous extreme value (MDCEV) model: role of utility function parameters, identification, considerations, and model extensions. Transportation Research Part B 42(3): 274-303.

Bhat CR, Guo JY (2007) A comprehensive analysis of built environment characteristics on household residential choice and auto ownership levels. Transportation Research Part B 41(5): 506-526.

Bhat CR, Srinivasan S, Sen S (2006) A joint model for the perfect and imperfect substitute goods case: application to activity time-use decisions. Transportation Research Part B 40(10): 827850.

Cervero R, Duncan M (2003) Walking, bicycling, and urban landscapes: evidence from the San Francisco Bay area. American Journal of Public Health 93(9): 1478-1483.

Chen Y, Ravulaparthy S, Deutsch K, Dalal P, Yoon SY, Lei T, Goulias KG, Pendyala RM, Bhat $\mathrm{CR}$, Hu H-H (2011) Development of indicators of opportunity-based accessibility. Transportation Research Record 2255: 58-68.

Cherchye L, Muynck TD, DeRock B (2011). Noncooperative household consumption with caring. Working paper, Tillburg Univeristy.

Chiappori P (1988) Rational Household Labor Supply. Econometrica 56(1): 63-90.

Del Boca D, Flinn C (2012) Endogenous household interaction. Journal of Econometrics 166(1): 49-65.

Fan Y, Khattak AJ (2009) Does urban form matter in solo and joint activity engagement? Landscape and Urban Planning 92(3-4): 199-209.

Gliebe JP, Koppelman FS (2002) A model of joint activity participation between household members. Transportation 29(1): 49-72.

Gliebe JP, Koppelman FS (2005) Modeling household activity-travel interactions as parallel constrained choices. Transportation 32(5): 449-471. 
Goulias KG, Bhat CR, Pendyala RM, Chen Y, Paleti R, Konduri KC, Lei T, Tang D, Youn SY, Huang G, Hu HH (2012) Simulator of activities, greenhouse emissions, networks, and travel (SimAGENT) in Southern California. Presented at the $91^{\text {st }}$ Annual Meeting of the Transportation Research Board, Washington, D.C., January.

Habib KMN, Miller EJ (2008) Modeling daily activity program generation considering withinday and day-to-day dynamics in activity-travel behaviour. Transportation 35(4): 467-484.

Habib KMN, Carrasco JA, Miller EJ (2008) Social context of activity scheduling: discretecontinuous model of relationship between 'with whom' and episode start time and duration. Transportation Research Record 2076: 81-87.

Hertzberg A (2012) Exponential individuals, hyperbolic households. Working paper, Finance and Economics, Columbia Business School, Columbia University.

Iso-Ahola SE (1983) Towards a social psychology of recreational travel. Leisure Studies 2(1): 45-56.

Kang H, Scott DM (2008) An integrated spatio-temporal GIS toolkit for exploring intrahousehold interactions. Transportation 35(2): 253-268.

Kapur A, Bhat CR (2007) On modeling adults' daily time use by activity purpose and accompaniment arrangement. Transportation Research Record 2021: 18-27.

Kato H, Matsumoto M (2009) Intrahousehold interaction in a nuclear family: a utilitymaximizing approach. Transportation Research Part B 43(2): 191-203.

Konduri K, Paleti R, Pendyala RM, Bhat CR (2011) A simultaneous equations choice model system of tour type, vehicle type, accompaniment, and tour length. Presented at the International Choice Modeling Conference, Leeds, UK.

Lu X, Pas EI (1999) Socio-demographics, activity participation and travel behavior. Transportation Research Part A 33(1): 1-18.

Lundberg S (2005) Sons, daughters, and parental behaviour. Oxford Review of Economic Policy 21(3): 340-356.

Mallet WJ, McGuckin N (2000) Driving to distractions: recreational trips in private vehicles. Transportation Research Record 1719: 267-272.

Mannering F, Murakami E, Kim SG (1994) Temporal stability of travelers' activity choice and home-stay duration: Some empirical evidence. Transportation 21(4): 371-392.

McGuckin N, Nakamoto Y (2004) Differences in trip chaining by men and women. Conference Proceedings 35, Research on Woman's Issues in Transportation-Vol. 2: Technical Papers, Transportation Research Board, The National Academies, Washington D.C.

Meloni I, Guala L, Loddo A (2004) Time allocation to discretionary in-home, out-of-home activities and to trips. Transportation 31(1): 69-96.

Miller EJ, Roorda MJ (2003) A prototype model of 24-hour household activity scheduling for the Toronto area. Transportation Research Record 1831: 114-121.

Paleti R, Copperman RB, Bhat CR (2010) An empirical analysis of children's after school out-of home activity-location engagement patterns and time allocation. Transportation 38(2): 273304. 
Pinjari AR, Bhat CR (2010a) A multiple discrete-continuous nested extreme value (MDCNEV) model: formulation and application to non-worker activity time-use and timing behavior on weekdays. Transportation Research Part B 44(4): 562-583.

Pinjari AR, Bhat CR (2010b) An efficient forecasting procedure for Kuhn-Tucker consumer demand model systems: application to residential energy consumption analysis. Technical paper, Department of Civil and Environmental Engineering, University of South Florida.

Pinjari AR, Bhat CR, Hensher DA (2009) Residential self-selection effects in an activity timeuse behavior model. Transportation Research Part B 43(7): 729-748.

Rajagopalan BS, Pinjari AR, Bhat CR (2009) Comprehensive model of worker nonwork-activity time use and timing behavior. Transportation Research Record 2134: 51-62.

Reisner E (2003) Understanding family travel demands as a critical component in work-family research, transportation and land-use. Presented at From 9 to 5 to 24/7: How Workplace Changes Impact Families, Work and Communities, Academic Work and Family Research Conference.

Ronald N, Dignum V, Jonker C, Arentze T, Timmermans H (2012) On the engineering of agentbased simulations of social activities with social networks. Information and Software Technology 54(6): 625-638.

Samuelson PA (1956) Social indifference curves. Quarterly Journal of Economics 70(1): 1-22.

Sener IN, Bhat CR (2007) An analysis of the social context of children's weekend discretionary activity participation. Transportation 34(6): 697-721.

Sener IN, Bhat CR, Pendyala RM (2011) When, where, how long, and with whom are individuals participating in physically active recreational episodes? Transportation Letters: The International Journal of Transportation Research 3(3): 201-217.

Sivakumar A, Bhat CR (2002) A fractional split distribution model for statewide commodity flow analysis. Transportation Research Record 1790: 80-88.

Srinivasan S, Athuru SR (2005) Analysis of within-household effects and between household differences in maintenance activity allocation. Transportation, 32(5), 495-521.

Srinivasan S, Bhat CR (2005) Modeling household interactions in daily in-home and out-ofhome maintenance activity participation. Transportation 32(5): 523-544.

Srinivasan S, Bhat CR (2006) A multiple discrete-continuous model for independent- and jointdiscretionary-activity participation decisions. Transportation 33(5): 497-515.

Stefan KJ, Hunt JD (2006) Age-based analysis of children in Calgary, Canada. Presented at the $85^{\text {th }}$ Annual Meeting of the Transportation Research Board, Washington D.C., January.

Timmermans HJP, Zhang J (2009) Modeling household activity travel behavior: example of state of the art modeling approaches and research agenda. Transportation Research Part B 43(2): 187-190.

Vovsha P, Bradley M (2006) Advanced activity-based models in context of planning decisions. Transportation Research Record 1981: 34-41.

Vovsha P, Petersen E, Donnelly R (2004) Impact of intrahousehold interactions on individual daily activity-travel patterns. Transportation Research Record 1898: 87-97. 
Wang D, Li J (2009) A model of household time allocation taking into consideration of hiring domestic helpers. Transportation Research Part B 43(2): 204-216.

Xia F, Yuan H, Lo HP (2009) A comparison of two models for the use of leisure time. Transportation and Geography 2, 941-950.

Yamamoto T, Kitamura R (1999) An analysis of time allocation to in-home and out-of-home discretionary activities across working days and non-working days. Transportation 26(2): 211-230.

Zhang J, Fujiwara A (2006) Representing household time allocation behavior by endogenously incorporating diverse intrahousehold interactions: a case study in the context of elderly couples. Transportation Research Part B 40(1): 54-74.

Zhang J, Timmermans H, Borgers A (2005) A model of household task allocation and time use. Transportation Research Part B 39(1): 81-95.

Zhang J, Kuwano M, Lee B, Fujiwara A (2009) Modeling household discrete choice behavior incorporating heterogeneous group decision-making mechanisms. Transportation Research Part B 43(2): 230-250. 
Table 1. Descriptive Analysis of Household-Level Participation and Daily Time Investment by Activity Purpose and Number of Participating Individuals

\begin{tabular}{|c|c|c|c|c|c|c|c|c|c|c|c|}
\hline \multirow{2}{*}{ Activity Purpose } & \multirow{2}{*}{$\begin{array}{c}\text { \% of } \\
\text { households } \\
\text { in which no } \\
\text { individual } \\
\text { participates } \\
\text { in “row" } \\
\text { activity } \\
\text { purpose }\end{array}$} & \multicolumn{5}{|c|}{$\begin{array}{l}\text { \% of households (from among those who } \\
\text { participate in row activity purpose) by } \\
\text { number of participating individuals }\end{array}$} & \multicolumn{3}{|c|}{$\begin{array}{l}\text { Mean duration of daily time } \\
\text { investment (minutes) across households } \\
\text { who participate in row activity purpose }\end{array}$} & \multicolumn{2}{|c|}{$\begin{array}{c}\text { \% of households (from } \\
\text { among those who } \\
\text { participate in activity } \\
\text { purpose) who participate... }\end{array}$} \\
\hline & & 1 & 2 & 3 & 4 & 5 & Overall & $\begin{array}{l}\text { Independent } \\
\text { (single } \\
\text { individual) }\end{array}$ & $\begin{array}{c}\text { Joint } \\
\text { (multiple } \\
\text { individuals) }\end{array}$ & $\begin{array}{l}\text { Only in } \\
\text { activity } \\
\text { purpose }\end{array}$ & $\begin{array}{l}\text { In other } \\
\text { activity } \\
\text { purposes too }\end{array}$ \\
\hline Shopping & 48.9 & 81.7 & 14.1 & 3.1 & 0.9 & 0.2 & 55.3 & 54.3 & 59.8 & 14.7 & 85.3 \\
\hline Maintenance & 51.5 & 89.1 & 10.4 & 0.5 & -- & -- & 90.3 & 90.4 & 89.7 & 14.1 & 85.9 \\
\hline Social & 91.4 & 83.9 & 13.5 & 1.5 & 0.9 & 0.2 & 134.8 & 137.8 & 119.6 & 8.8 & 91.2 \\
\hline Entertainment & 89.9 & 80.9 & 15.5 & 3.1 & 0.5 & -- & 302.2 & 315.8 & 244.1 & 9.2 & 90.8 \\
\hline Visiting & 80.6 & 85.3 & 11.1 & 2.5 & 0.9 & 0.2 & 195.8 & 198.9 & 137.8 & 11.9 & 88.1 \\
\hline Active Recreation & 83.8 & 85.5 & 11.4 & 2.6 & 0.4 & 0.1 & 143.0 & 141.6 & 152.2 & 12.0 & 88.0 \\
\hline Eat-out & 67.6 & 79.4 & 16.6 & 2.8 & 1.0 & 0.2 & 56.2 & 55.6 & 58.3 & 9.3 & 90.7 \\
\hline Other & 79.8 & 80.1 & 15.7 & 3.1 & 1.0 & 0.1 & 191.6 & 208.4 & 124.3 & 7.9 & 92.1 \\
\hline Work-related & 87.8 & 100.0 & -- & -- & -- & -- & 294.5 & 294.5 & -- & 15.9 & 84.1 \\
\hline
\end{tabular}


Table 2. MDCEV Model Estimation Results

\begin{tabular}{|c|c|c|}
\hline Explanatory Variables & Parameter & T-Statistic \\
\hline \multicolumn{3}{|c|}{$\begin{array}{l}\text { Household Demographics } \\
\text { Number of school going children }\end{array}$} \\
\hline \multicolumn{3}{|c|}{ Activity Purpose (Base is maintenance activity purpose) } \\
\hline Shopping & -0.1310 & -4.64 \\
\hline Entertainment & -0.0685 & -1.71 \\
\hline Visiting Friends & 0.0245 & 0.76 \\
\hline Active Recreation & 0.1937 & 6.40 \\
\hline Eat-out & -0.2837 & -8.99 \\
\hline Other & 0.6362 & 21.60 \\
\hline Work-related & 0.2141 & 5.57 \\
\hline \multicolumn{3}{|c|}{ Number of non-school going children } \\
\hline \multicolumn{3}{|c|}{ Activity Purpose (Base is maintenance activity purpose) } \\
\hline Shopping & -0.1552 & -6.48 \\
\hline Social & -0.3225 & -5.90 \\
\hline Eat-out & -0.1614 & -5.59 \\
\hline Other & 0.6661 & 24.31 \\
\hline Work-related & 0.1396 & 4.70 \\
\hline \multicolumn{3}{|l|}{ Number of senior adults } \\
\hline \multicolumn{3}{|c|}{ Activity Purpose (Base is work-related activity purpose) } \\
\hline Shopping & 0.7655 & 13.85 \\
\hline Maintenance & 0.8667 & 15.97 \\
\hline Social & 0.9842 & 14.32 \\
\hline Entertainment & 0.7563 & 11.06 \\
\hline Visiting Friends & 0.6253 & 10.03 \\
\hline Active Recreation & 0.7765 & 12.44 \\
\hline Eat-out & 0.7329 & 12.15 \\
\hline Other & 0.4794 & 6.57 \\
\hline \multicolumn{3}{|c|}{ High Income Household (Income $>\$ 100 K$ ) } \\
\hline \multicolumn{3}{|c|}{ Activity Purpose (Base is work-related and active recreation purposes) } \\
\hline Shopping & -0.2266 & -5.02 \\
\hline Maintenance & -0.2331 & -5.13 \\
\hline Social & -0.4273 & -4.46 \\
\hline Entertainment & -0.3192 & -4.20 \\
\hline Visiting Friends & -0.6557 & -10.40 \\
\hline Other & -0.3073 & -4.65 \\
\hline \multicolumn{3}{|c|}{ Number of participating people } \\
\hline One & 0.5217 & 6.21 \\
\hline At least two people & 0.1014 & 1.22 \\
\hline \multicolumn{3}{|l|}{ Total number of vehicles } \\
\hline \multicolumn{3}{|c|}{ Activity Purpose (Base is work-related activity purpose) } \\
\hline Shopping & -0.2408 & -10.32 \\
\hline Maintenance & -0.2830 & -12.71 \\
\hline Social & -0.1679 & -4.92 \\
\hline Entertainment & -0.2340 & -7.38 \\
\hline Visiting Friends & -0.1243 & -4.66 \\
\hline Active Recreation & -0.1513 & -5.30 \\
\hline Eat-out & -0.2391 & -9.45 \\
\hline Other & -0.2753 & -9.05 \\
\hline
\end{tabular}


Table 2. (Continued) MDCEV Model Estimation Results

\begin{tabular}{|c|c|c|}
\hline Explanatory Variables & Parameter & T-Statistic \\
\hline \multirow{2}{*}{\multicolumn{3}{|c|}{$\begin{array}{l}\text { Individual Characteristics } \\
\text { Latest Work End time among people in the alternative (in minutes/100) } \\
\text { Activity Purpose }\end{array}$}} \\
\hline & & \\
\hline Shopping & -1.3213 & -7.84 \\
\hline Social & -1.0581 & -2.40 \\
\hline Entertainment & -0.6481 & -5.59 \\
\hline Active Recreation & -0.7700 & -2.71 \\
\hline Other & -2.3252 & -7.84 \\
\hline Work-related & -3.1325 & -14.32 \\
\hline \multicolumn{3}{|l|}{ Maximum Work Duration among people in the alternative (in minutes/100) } \\
\hline \multicolumn{3}{|l|}{ Activity Purpose } \\
\hline Shopping & -1.1533 & -19.09 \\
\hline Maintenance & -1.1533 & -19.09 \\
\hline Social & -0.3768 & -1.44 \\
\hline Active Recreation & -0.0230 & -0.13 \\
\hline Eat-out & 0.1888 & 4.41 \\
\hline Other & 0.3310 & 1.96 \\
\hline Work-related & 0.8254 & 6.70 \\
\hline \multicolumn{3}{|l|}{ Number of children among the people in the alternative } \\
\hline \multicolumn{3}{|l|}{ Number of participating people } \\
\hline One & -0.6390 & 4.83 \\
\hline \multicolumn{3}{|l|}{ Interaction of Number of participating people and activity purpose } \\
\hline Shopping*At least two participating people & 0.4571 & 9.44 \\
\hline Maintenance*At least two participating people & -0.6403 & 7.53 \\
\hline Social*At least two participating people & 0.4571 & 9.44 \\
\hline Entertainment*At least two participating people & 0.0400 & 0.55 \\
\hline \multicolumn{3}{|l|}{ Number of adults with school drop-off/pick-up commitments in the alternative } \\
\hline \multicolumn{3}{|l|}{ Activity Purpose } \\
\hline Shopping & 0.5599 & 7.53 \\
\hline Maintenance & 0.3900 & 4.83 \\
\hline Eat-out & 0.8028 & 9.44 \\
\hline Work-related & -0.5051 & -3.34 \\
\hline \multicolumn{3}{|l|}{ Presence of a woman adult and a child in the alternative } \\
\hline \multicolumn{3}{|l|}{ Number of participating people } \\
\hline At least two people & 0.0362 & 1.32 \\
\hline \multicolumn{3}{|l|}{ Accessibility Measures } \\
\hline \multicolumn{3}{|l|}{ Retail and Service Employment Accessibility } \\
\hline \multicolumn{3}{|l|}{ Activity Purpose } \\
\hline Shopping & 0.0137 & 2.30 \\
\hline Maintenance & 0.0107 & 1.82 \\
\hline Entertainment & 0.0221 & 2.13 \\
\hline Active Recreation & 0.0709 & 8.57 \\
\hline Eat-out & 0.0458 & 6.69 \\
\hline \multicolumn{3}{|l|}{ Population Accessibility } \\
\hline \multicolumn{3}{|l|}{ Activity Purpose } \\
\hline Shopping & -0.0077 & -4.09 \\
\hline Maintenance & -0.0058 & -3.10 \\
\hline Entertainment & -0.0082 & -2.51 \\
\hline Active Recreation & -0.0230 & -8.45 \\
\hline Eat-out & -0.0174 & -7.86 \\
\hline
\end{tabular}


Table 3. Validation Results of the Final MDCEV Model

\begin{tabular}{|c|c|c|c|c|c|c|c|}
\hline \multirow{2}{*}{ Activity Type } & \multirow{2}{*}{$\begin{array}{c}\text { \% of Households in } \\
\text { which no individual } \\
\text { participates in activity }\end{array}$} & \multicolumn{5}{|c|}{$\begin{array}{l}\text { \% of HHs (from among those who participate in row activity) by number of } \\
\text { participating individuals }\end{array}$} & \multirow{2}{*}{$\begin{array}{c}\text { Predicted } \\
\text { Mean duration } \\
\text { of participation } \\
\text { (minutes) }\end{array}$} \\
\hline & & 1 & 2 & 3 & 4 & 5 & \\
\hline Shopping & 56.2 (48.9) & $82.3(81.7)$ & $13.7(14.1)$ & $3.0(3.1)$ & $0.9(0.9)$ & $0.2(0.2)$ & $98.1(55.3)$ \\
\hline Maintenance & $53.0(51.5)$ & 89.7 (89.1) & $8.9(10.4)$ & $1.2(0.5)$ & $0.2(0.0)$ & -- & $92.5(90.3)$ \\
\hline Social & $91.3(91.4)$ & 89.2 (83.8) & 8.5 (13.5) & $1.3(1.5)$ & $1.0(0.9)$ & $0.0(0.2)$ & $163.5(134.8)$ \\
\hline Entertainment & 88.1 (89.9) & 84.6 (80.9) & $12.8(15.5)$ & $2.0(3.1)$ & $0.5(0.5)$ & $0.1(0.0)$ & $218.6(302.2)$ \\
\hline Visiting Friends & $78.9(80.6)$ & 86.3 (85.3) & $11.3(11.1)$ & $1.8(2.5)$ & $0.5(0.9)$ & $0.1(0.2)$ & $181.4(195.8)$ \\
\hline Active Recreation & 82.9 (83.8) & $89.3(85.5)$ & 8.7 (11.4) & $1.2(2.6)$ & $0.7(0.4)$ & $0.1(0.1)$ & $167.4(143.0)$ \\
\hline Eat-out & $69.3(67.4)$ & $83.1(79.4)$ & $14.2(16.6)$ & $2.1(2.8)$ & $0.5(1.0)$ & $0.1(0.2)$ & $78.1(56.2)$ \\
\hline Other & $87.4(79.8)$ & $82.9(80.1)$ & $12.4(15.7)$ & $3.4(3.1)$ & $1.0(1.0)$ & $0.3(0.1)$ & 167.6 (191.6) \\
\hline Work-related & $78.6(87.8)$ & 100.0 & -- & -- & -- & -- & 262.7 (294.5) \\
\hline
\end{tabular}

